\title{
Insurgencia, planificación y la perspectiva de un urbanismo humano ${ }^{*, *}$
}

\author{
Faranak Miraftab ${ }^{\star * \star}$
}

Muchas gracias por esta presentación. Inicialmente, me gustaría agradecer a la comisión organizadora del World Planning Schools Conference por haberme invitado para dar apertura a este importante diálogo entre colegas del mundo entero. Es una verdadera honra y un privilegio dirigirme a un grupo de estudiosos de renombre internacional, siendo incluso que de varios de ellos sigo aprendiendo. Como siempre, el conocimiento es una producción colectiva, y, por lo tanto, lo que voy a compartir con ustedes en el día de hoy son mis conocimientos, adquiridos a través del diálogo con activistas y académicos de todo el mundo.

No es necesario decirle a esta audiencia que vivimos en un momento de crisis, una crisis global que no es solamente una crisis del capitalismo, sino también de la planificación como una profesión y como una idea. Por eso la urgencia de nuestras conversaciones en este congreso mundial, para discutir cómo podemos repensar la planificación, la cual hace parte de esta crisis contemporánea, e imaginar prácticas de decolonización que hagan posible un urbanismo humano. La crisis contemporánea es insidiosa e infecta todas las dimensiones de la vida en todos los rincones del mundo. Pero eso no significa que todos estemos en ella de la misma forma; esas crisis afectan de formas diferentes a distintas personas, de formas que son injustas y desiguales. Poderosas economías, que producen la deshumanización de las crisis globales, rara vez asumen la responsabilidad por su creación. La actual guerra en Oriente Medio y su desplazamiento global es un ejemplo.

Hoy más de 60 millones de personas, es decir, una de cada 122 personas en el mundo, fueron expulsadas de sus hogares por la guerra y otros peligros; un sufrimiento cuya magnitud es la peor de las observadas en comparación con otros momentos de la historia humana. Pero, mientras el mundo ve a casi un millón de personas huyendo y cruzando valientemente el Mar Mediterráneo para alcanzar Europa, solamente cerca

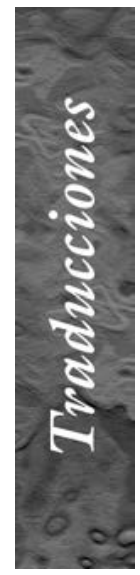

* El presente artículo fue publicado originalmente en portugués en la Revista Brasilera de Estudios Urbano Regionales RBEUR Vol. 18, n. 3 de sep.-dic. del 2016, pp. 363-377. Esta traducción cuenta con la autorización del comité editorial de dicha revista y de la autora. La traducción al españolba sido realizada por Hernando Sáenz Acosta, docente de la Facultad de Sociología de la Universidad Santo Tomás, Bogotá, Colombia.

** Conferencia de apertura del IV World Planning Schools Congress, realizado en Rio de Janeiro el 3 de julio del 2016. Traducción del inglés al portugués de Esther Limonad, docente del programa de posgrado en Geografía de la Universidad Federal Fluminense (POSGEO/UFF). 
$\Leftarrow$

*** Ph. D. Universidad de California, Berkeley 1995. Profesora de Planificación Urbana y Regional en la Universidad de Illinois, Urbana-Champaign, Estados Unidos. Correo electrónico:faranak@illinois.edu 1 Véase https://www.foreignaffairs.com/articles/ levant/2015-10-20/helprefugees-help-themselves

territarios 38 de 300000 reciben la llamada "hospitalidad europea". La gran mayoría de los refugiados permanece cerca de sus hogares, sin mucha atención mundial, en lugares como Turquía, Jordania, el Líbano, Irak, Irán y Egipto, en campos de refugiados como Zaatari en Jordania, los cuales son ahora una característica permanente de las ciudades y una forma de urbanización ${ }^{1}$.

Esta es, de hecho, una era de destierro global, sea por causa de las guerras y del petróleo, sea por causa de las ganancias del capital inmobiliario que genera expoliación y expulsión urbanas.

En cuanto Congreso Mundial de Escuelas de Planificación (WPSC - World Plan- ning Schools Congress, 2016), los debates en que nos embarcaremos en los próximos días conciernen al cómo nosotros, en cuanto académicos de la planificación, respondemos y nos involucramos en relación con esa crisis e injusticia mediante el entrenamiento de las próximas generaciones de profesionales.

Argumento que la planificación se está enfrentando con su propia crisis de identidad y legitimidad, una crisis que emerge de su esquizofrenia profesional, razón por la que su propia imagen e idea de la profesión no se encajan. De ahí, por lo tanto, la necesidad de un nuevo tipo de planificación, de un nuevo significado y de una

Figura 1. Campo de refugiados Zaatari, Jordania, 80000 personas

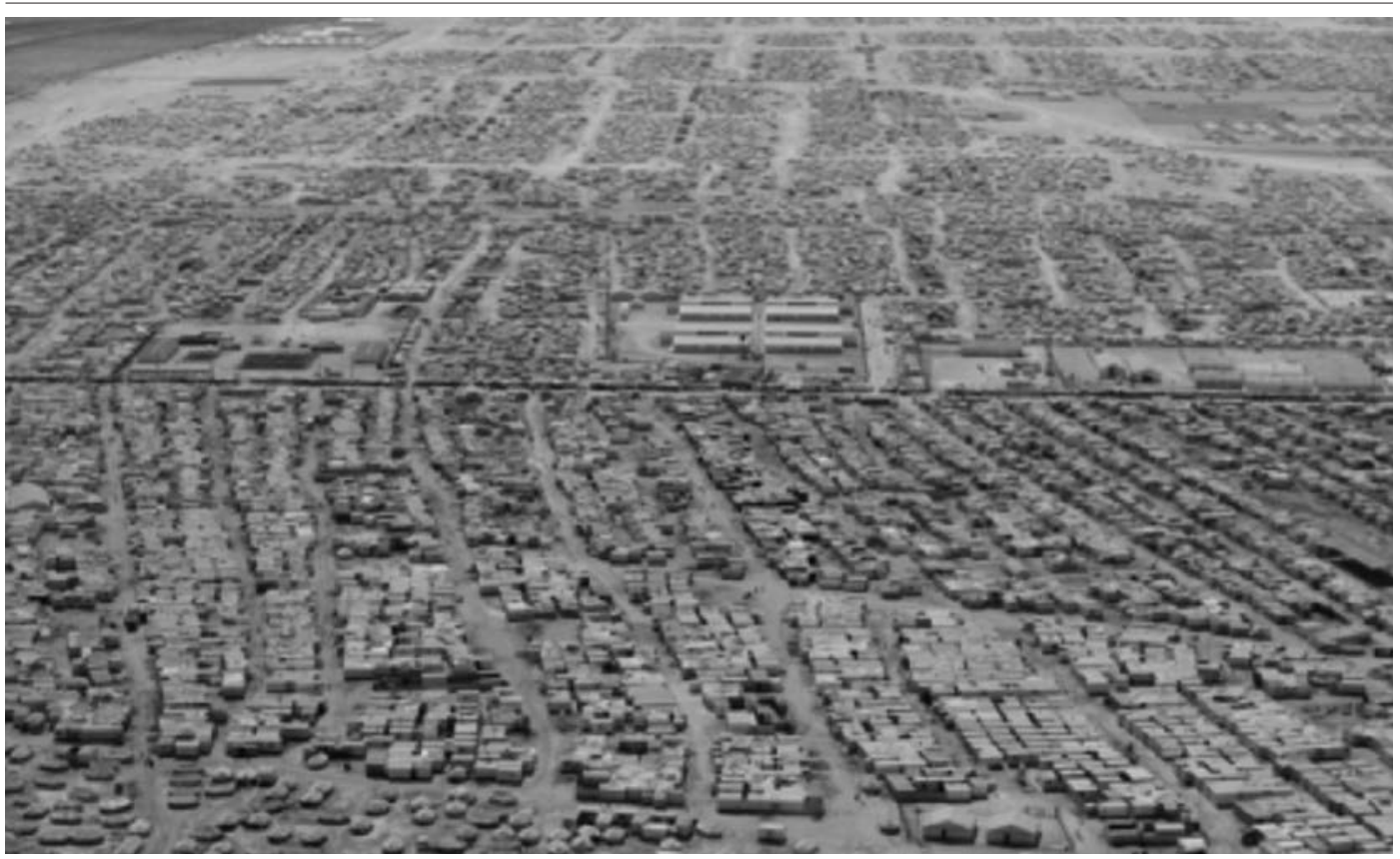

Fuente: Tomada de https://www.foreignaffairs.com/articles/levant/2015-10-20/help-refugees-help-themselves 
nueva imaginación. La planificación progresista necesita romper con los postulados que la condujeron a tal crisis existencial. Necesita de un cambio ontológico en la teorización de las prácticas de la planificación. Algunos la designan de planificación insurgente, otros, incluso aquí algunos de mis colegas de Río de Janeiro, la llaman de planificación conflictual.

En esta presentación me enfoco en lo que se requiere en la teorización de las prácticas de planificación para tal ruptura ontológica. En primer lugar, reconocer el abanico de prácticas existentes que van más allá de las que son sancionadas por el Estado y los poderes corporativos - a las que llamo prácticas insurgentes-; $\mathrm{y}$, en segundo lugar, decolonizar la imaginación y las posibilidades para el futuro. Para eso necesitamos recurrir a las prácticas subordinadas, maduradas en movimientos anticoloniales y anticapitalistas de larga duración. Ahí encontraremos la inspiración, los valores y los principios orientadores para prácticas que pueden promover un futuro y un urbanismo más humanos.

Déjenme desarrollar esa argumentación paso a paso. Voy a hacerlo en tres actos:

Acto I: La esquizofrenia de la planificación

Acto II: Prácticas insurgentes como un tipo diferente de planificación

Acto III: Imaginación y urgencia de decolonizar el futuro
$\mathrm{Y}$, entonces, finalizaré con una breve reflexión sobre lo que todo esto representa para la enseñanza de la planificación.

\section{Acto I: La esquizofrenia de la planificación}

La planificación en tanto profesión se auto-enaltece por atender al bien público, pero los planificadores profesionales se encuentran generalmente al servicio del bien privado.

Esa esquizofrenia de la planificación es puesta al desnudo cuando: la promoción de los conjuntos habitacionales de ingresos mixtos en Chicago se traduce en la remoción de los habitantes pobres y racialmente discriminados de los conjuntos habitacionales públicos (figuras 2 y 3 ).

En Chicago, conforme se elevaron los precios de los inmuebles y la localización de los conjuntos habitacionales públicos se tornó atractiva en términos financieros, se demolieron estos últimos en pro del desarrollo de comunidades de ingresos mixtos. El resultado de la planificación que estaba dirigida para la integración habitacional fue la expulsión por gentrificación, por ejemplo el alquiler de nuevos apartamentos de dos cuartos en esa área es superior a los 3000 dólares $^{2}$.

Esta esquizofrenia de la planificación es puesta al desnudo cuando:

Transportes eficientes en Mumbai se traducen en expoliación y expulsión.

El proyecto de la autopista costera en Mumbai promete una combinación de $33,20 \mathrm{~km}$ de "puentes sobre el mar, vías
2 Véase http://picturethehomeless.org/wp-content/ uploads/2015/12/Homeless_People_Count2.pdf territarias 38 217 


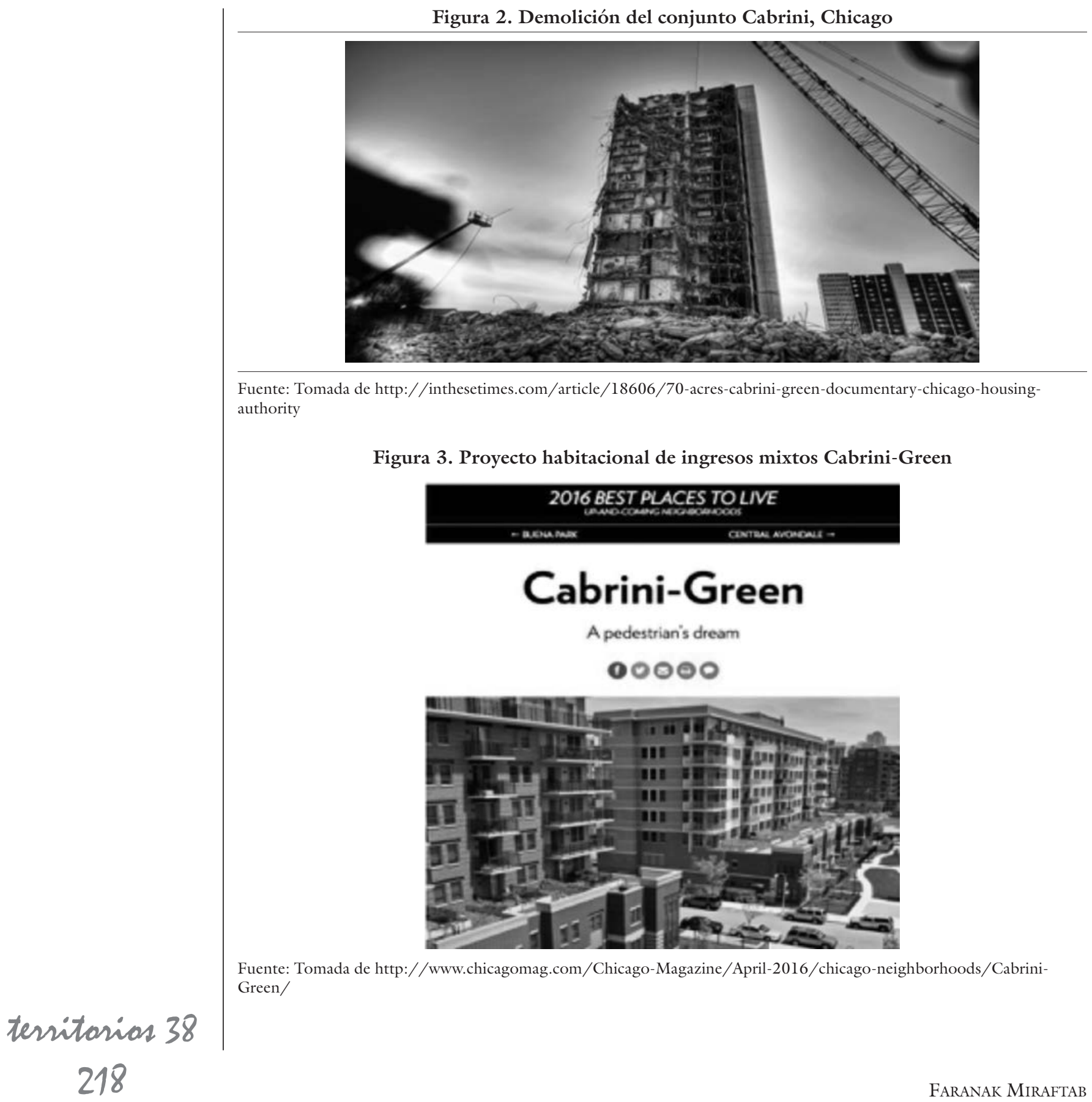


elevadas, suelo recuperado y túneles submarinos"3 para atravesar la bahía, reducir los atascos en el tráfico y los niveles de polución en Mumbai. Los planificadores también prometen significativos embellecimientos y paisajismo ambiental que irán a aumentar la calidad de vida.

Sin embargo, el Tribunal del Pueblo Independiente, trabajando con el Colectivo de Mumbai por Alternativas Espaciales, muestra que "la autopista atenderá apenas a poco más del $1 \%$ de la población de Mumbai"4 — aquellos que manejan autos y viajan directamente en la parte más desarrollada de la Costa Oeste de la ciudad-. Peor aún, el proyecto destruirá la ecología costera y el sustento de las comunidades costeras de pescadores cuyas vidas dependen de la franja costera.

Aunque la planificación del transporte justifique y promueva un megaproyecto a nombre del bien común, últimamente lo vemos sirviendo a los promotores y al capital inmobiliario.

Esa esquizofrenia de la planificación es puesta al desnudo cuando:

En Cape Town - Sudáfrica, la planificación empresarial se traduce en la transferencia del costo de la revitalización económica a cargo de los municipios pobres. Mientras esa recuperación urbana del Mejoramiento de los Barrios de la Ciudad (City Improvement Districs, CID) trajo "I love my laundry café" (figura 4) para el vecindario del centro, donde Érika puede disfrutar su vino, café e internet mientras lava su ropa, para Nomvisiswano nunca se hizo realidad la promesa constitucional
Figura 4. Tienda de la red I Love my Laundry, Cape Town, Sudáfrica

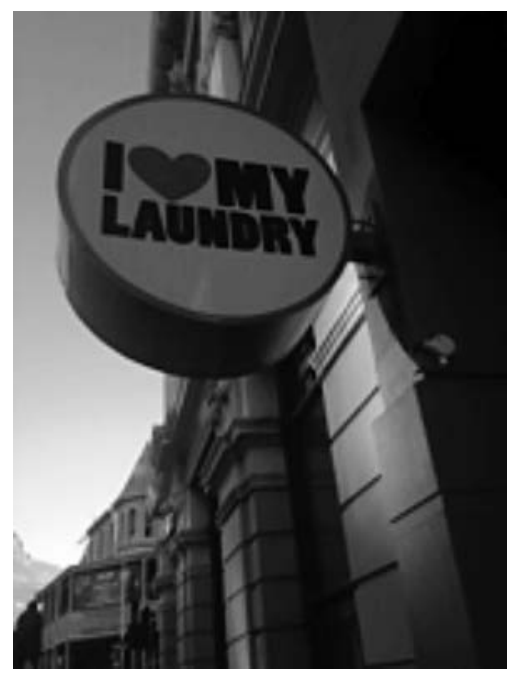

Fuente: Tomada de http://showme.co.za/cape-town/ news/i-love-my-laundry-in-buitenkant-street-openingnight/

de su derecho a servicios básicos. Lavar ropas es una batalla diaria en una de las pocas fuentes comunales en la periferia del asentamiento de Marikana, en Phillippi (figura 5).

Cuando los planificadores profesionales acordaron hace más de una década la creación del Mejoramiento de los Barrios de la Ciudad (CIDs) prometieron que dicho mejoramiento de los barrios revitalizados sería para toda la población. Sin embargo, no fue así para Nomvisiswano ni para millones de otros más.

De hecho, el problema es mucho peor. La falta de agua y de saneamiento básico está conectada de forma alarmante con la violencia de género. Véase el caso de dos
3 Véase https://csaweb. org/2015/10/09/mumbais-coastal-road-socialenvironmental-impacts/

4 Véase https://csaweb. org/2015/10/09/mumbais-coastal-road-socialenvironmental-impacts/

territarios 38 219 
5 Véase http://www.bbc. com/news/world-asia-india- 22460871

\section{territarias 38}

Figura 5. Nomvisiswano lavando su ropa en la periferia del asentamiento de Marikana en Phillipi

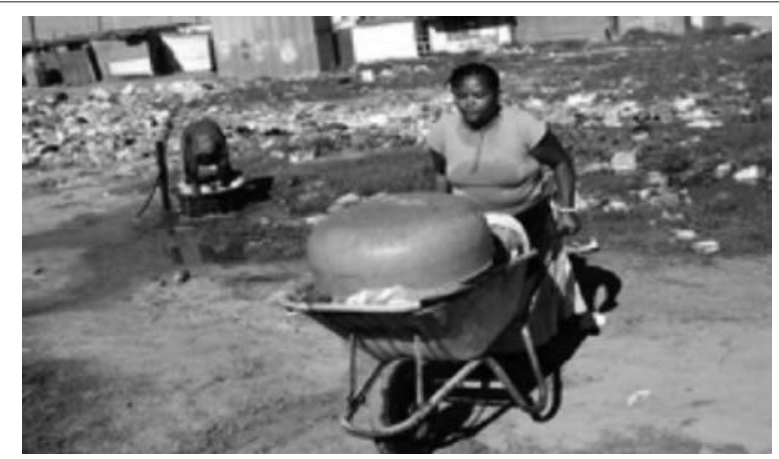

Fuente: Tomada de http://www.groundup.org.za/article/marikana-residents-struggle-water/

hermanas adolescentes del Estado de Bihar en la India, las cuales, en una tarde de mayo del 2012, salieron de su choza para defecar fuera de ella, lejos de todos, donde no fueran vistas y tuvieran privacidad. Sin embargo, nunca regresaron. Sus cuerpos muertos y violentados fueron encontrados después, colgados de un árbol de mangos.

Si las mujeres tuvieran acceso seguro a los baños, podrían haberse evitado cerca de unas 400 violaciones en aquel mismo año, solamente en Bihar, relataba el jefe de policía de dicho Estado ${ }^{5}$.

Es claro que este asunto afecta a muchas más personas y va más allá de las fronteras de Bihar.

Pero ¿̨cómo ha servido la profesión de la planificación al bien público en un caso tan grave de injusticia espacial? ¿Las jóvenes y las mujeres no son suficientes como un "público"? ¿Y su seguridad y vida no son suficientes como un bien?
La cuestión de fondo es que el Estado capitalista y los especialistas que buscan mantener el statu quo a través de la inclusión democrática liberal se enfrentan con las limitaciones de su promesa.

La planificación, como la conocemos, está enfrentándose con una crisis de legitimidad. Sus contradicciones y falsas promesas se manifiestan en crecientes desigualdades. Y las injusticias espaciales que promueve son evidencia patente de un "emperador sin ropa".

- Necesitamos de un tipo diferente de planificación

- De hecho no solo la necesitamos, sino que otro tipo de planificación es posible

- ¿Dónde podemos ver esto?

Muchos ciudadanos en el mundo se han tomado por cuenta propia a sus respectivas ciudades. De Gezi Park en Estambul, 
a la zona sur de Chicago, a los piqueteros en Buenos Aires, todos dicen: “¡basta! Ya tuvimos suficiente, ¡que se vayan todos!”.

Necesitamos considerar esas prácticas seriamente y reconocerlas como instancias del hacer ciudad, como ejemplos de las personas planificando sus propios futuros, un futuro que corporiza un urbanismo humano - algo que la profesión de la planificación tal como la conocemos falló en realizar-.

Para discutir esas experiencias como nuevas prácticas de planificación, necesitamos una nueva imaginación, un nuevo léxico, un nuevo repertorio de prácticas y una comprensión distinta de justicia.

La planificación insurgente puede ser la estructura que pavimenta ese camino hacia un urbanismo humano.

- Más aún, ¿̇cómo es esa planificación insurgente? ¿A qué se parece?

- ¿Cómo reconocerlo cuando lo veamos?

- ¿Cuáles son sus principios rectores, valores, ideales, imaginaciones y cómo procede a una ruptura fundamental con la planificación tal y como la conocemos?

Ese es el tema que abordo en el Acto II.

\section{Acto II: Prácticas insurgentes como un tipo diferente de planificación}

La planificación insurgente es una planificación alternativa hecha a la medida y tiene lugar entre comunidades subordi- nadas, sean asentamientos informales y municipios en excolonias o comunidades desfavorecidas en el estómago de la bestia - Norteamérica y Europa Oriental-.

En esta etapa histórica particular del neoliberalismo, donde la inclusión es una coartada para la exclusión y normalización de la dominación neocolonial, la falencia de la planificación inclusiva liberal nos presiona a repensar los parámetros epistemológicos y ontológicos de las teorizaciones y prácticas de planificación. Nosotros somos presionados a re-centralizar la política de la justicia en la teorización de la planificación y a romper con las filosofías políticas que la guiaron durante buena parte del siglo xx. La planificación insurgente, considero, persigue tal ruptura ontológica y epistemológica en nuestra coyuntura neoliberal contemporánea.

La planificación insurgente proviene de una tradición radical anterior en la teoría de la planificación, formulada inicialmente por Friedmann (2011) a final de los años ochenta, y después desarrollada por Sandercock (1998), Beard (2002) y otros autores que hicieron un llamado por el reconocimiento de las prácticas ciudadanas como formas de planificación.

La planificación insurgente da continuidad a esa tradición al abrir la teorización de la planificación a otras formas de acción, para incluir no solo formas seleccionadas de acción de los ciudadanos y de sus organizaciones sancionadas por los grupos dominantes, las cuales designo de espacios de acción convidados; sino también las insurrecciones e insurgencias que territarias 38

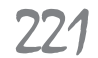


el Estado y las corporaciones sistemáticamente buscan colocar en el ostracismo y criminalizar, las cuales designo de espacios de acción inventados.

Esto, argumento, no es solo epistemológico (inclusión de comunidades locales y de voz y conocimiento local) sino también ontológico.

Activistas insurgentes ponen en práctica una distinta comprensión de justicia. Para alcanzar un resultado, ellos mudan la base de su clamor por justicia, de la concepción de justicia de Rawls (1971), en cuanto a igualdad, a la noción de Young (1990) de la justicia basada en el reconocimiento de la diferencia y de su política. Ellos entienden que no es suficiente con garantizar derechos individuales y un tratamiento igualitario como aboga la filosofía política liberal de la justicia. Al contrario, reclaman el reconocimiento urgente de formas de opresión auto-determinadas y basadas en grupos.

Tal comprensión de la justicia hace que el debate de la inclusión pase de la representación a la autodeterminación, un cambio en la perspectiva que valida la acción directa colectiva de los ciudadanos y que lleva a que se pase de la democracia representativa a la democracia participativa. En la democracia representativa, los ciudadanos delegan sus derechos a otros -representantes políticos, burócratas o especialistas técnicos- para actuar en su mejor interés. En contraste, en la democracia participativa los ciudadanos reconocen la inadecuación de los derechos formales y no le ceden a otros la defensa de sus intereses, sino, al contrario, toman parte directamente y formulan decisiones que afectan sus vidas. La democracia participativa consecuentemente promueve una forma de ciudadanía que es multicentrada y que tiene múltiples actividades, incluyendo los ciudadanos y sus acciones sociales directas.

Esto tiene importantes implicaciones para la planificación, porque rompe ontológicamente con la noción liberal de inclusión, que orientó la planificación profesional durante la mayor parte del siglo $\mathrm{XX}$. Las prácticas insurgentes generan una ruptura ontológica, ya que no se trata de conseguir una porción mayor de la torta, sino de desear otro tipo de torta - una torta ontológicamente distinta-. Las prácticas insurgentes y la planificación insurgente no buscan la inclusión a través de una mejor representación (sea de especialistas o de políticos); sino que buscan la inclusión auto-determinada, en la cual los derechos de las personas son reales y practicados.

Conforme la planificación insurgente descentraliza el papel de la representación y presta más atención a la acción directa y a los medios de inclusión, muda también el sujeto de su teorización - del planificador a la planificación-. En la arquitectura conceptual de la planificación insurgente, los planificadores profesionales son solamente un actor en un conjunto más amplio que conforma el cuestionable campo de acción conocido como planificación. La preocupación principal es, por lo tanto, por las prácticas y no por sus actores. 
En la medida en que los espacios de acción convidados e inventados de los ciudadanos son críticos para mi abordaje de la planificación insurgente, tomaré unos breves momentos para aclarar el concepto.

Los dos tipos de espacios que discuto se encuentran en una relación dialéctica y de interacción mutuamente constituida, no en una relación binaria. Evidencias concretas muestran que las prácticas de los movimientos sociales, que buscan alcanzar más allá que las necesidades individuales — que es la meta de la inclusión liberal- tienen que moverse frecuentemente a través y entre aquellos espacios de acuerdo con las necesidades específicas de lucha. Pero las instituciones de poder, tales como los medios de comunicación dominantes, el Estado, las organizaciones internacionales de ayuda, configuran esos espacios convidados e inventados en una relación binaria, y tienden a criminalizar estos últimos, designando apenas a los primeros como espacios "apropiados" para las voces y la participación de los ciudadanos.

Debemos observar que una construcción binaria de espacios convidados e inventados se arriesga a una concepción fija equivocada de estabilidad en cada espacio. Esa construcción binaria desconsidera la flexibilidad y la naturaleza innovadora del capitalismo y del cómo él se desdobla sobre lo que quiera que esté en el margen y busca incorporar lo que considera puede constituir una amenaza. Lo que hoy es una alternativa puede volverse mañana una tendencia dominante y despolitizada por la represión y cooptación, con su fuer- za transformadora minada, dejando a los activistas con un "teléfono de juguete sin señal para llegar a lugar alguno"; metáfora que mi colega Ken Salo usa para esos movimientos robados.

Los movimientos radicales necesitan, entonces, reinventar constantemente sus espacios de acción a través de "prácticas de ruptura y creación". Porque, como afirma Marcelo Svirsky (2010), el activismo que "anda caminos de disensos reconocidos está siempre bajo la amenaza de ser sitiado y contenido por el organismo del Estado", y de la conformidad a la complicidad es un paso muy corto, como advierte Buchanan (2000). El activismo que solo busca garantizar los mecanismos de la democracia representativa constituye lo que Svirsky (2010) llama "activismo esclavo".

Ese tipo de activismo esclavo es el que la teoría despolitizada de la planificación celebró y popularizó como la planificación inclusiva a través de la participación ciudadana, del desarrollo comunitario de movimientos sociales y del envolvimiento de movimientos sociales. La planificación insurgente rompe con ese modo de pensar de manera radical. La planificación insurgente desafía el confinamiento y la confirmación de las acciones de los ciudadanos a las normas del Estado democrático liberal y del aparato de mercado y también reconoce cómo los ciudadanos pueden usar esas normas para inducir una ruptura y crear algo nuevo.

Los escépticos, cuestionan aún aspectos importantes: territarias 38

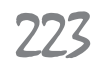


- ¿Cómo reconocemos las prácticas insurgentes que contribuyan para construir una democracia participativa y para crear las bases necesarias para desarrollar un urbanismo humano?

- ¿ ¿Será que todo acto de insurrección o disruptivo constituye una contribución progresista a un urbanismo humano? $\mathrm{O}$, ¿̨puede ser antidemocrático, reaccionario o, más aun, fascista?

Se puede tomar por ejemplo el caso Clive Bundy (figura 6), en los Estados Unidos, un movimiento de la derecha que participó, durante casi seis semanas, en una ocupación y una confrontación armada con las autoridades de Nevada en relación con los derechos de pastizaje del ganado en un área de preservación de vida silvestre. Los insurgentes Clive Bundy y sus hijos, con el apoyo de otros vaqueros, resistieron a la imposición de tributación federal.

Consideremos también los diferentes disturbios xenofóbicos en Sudáfrica, incluso el del 2015, en Cabo occidental, donde tuve el infortunio de presenciar los testimonios de sus víctimas, que rompen el corazón, entre los que están refugiados y migrantes pobres africanos.

Entiendo las prácticas de planificación insurgente, con potencial transformador para un urbanismo humano, en términos de tres principios:

- Transgresión en tiempo, lugar y acción: ellas transgreden falsas dicotomías en-

\section{territarias 38} 224 ras nacionales al construir solidaridades transnacionales y se mueven más allá de los lazos del tiempo a través de una consciencia historicizada.

- Contra y anti-hegemonía: las prácticas de la planificación insurgente son anti y contra-hegemónicas. Ellas desestabilizan relaciones de dominación y son específicamente anticapitalistas.

- Imaginación las prácticas de planificación insurgente son imaginativas. Recuperan el idealismo por una sociedad justa.

Algunos ejemplos pueden ayudar. Comienzo con un breve ejemplo de un proyecto en curso titulado "Medio-Oeste insurgente: diálogos transnacionales para un urbanismo humano" ("Insurgent Midwest: Transnational Dialogues for Humane Urbanism"), en el que estoy involucrada con un colectivo de académicos y activistas en Illinois.

Uno de los grupos incluidos en ese proyecto es el Centro Autónomo de Albany Park - Red Mexicana de Solidaridad (Albany Park Autonomous Center - Mexican Solidarity Network - MSN) - , organización de base comunitaria con sede en Albany Park, un barrio de Chicago con un gran contingente de inmigrantes y latinos, pero asociada y articulada en red con movimientos de México. Trabaja estrechamente con los zapatistas, con comunidades indígenas y campesinas, con frentes de trabajo en Chiapas, Ciudad Juárez, Guerrero, Oaxaca, Ciudad de México. 


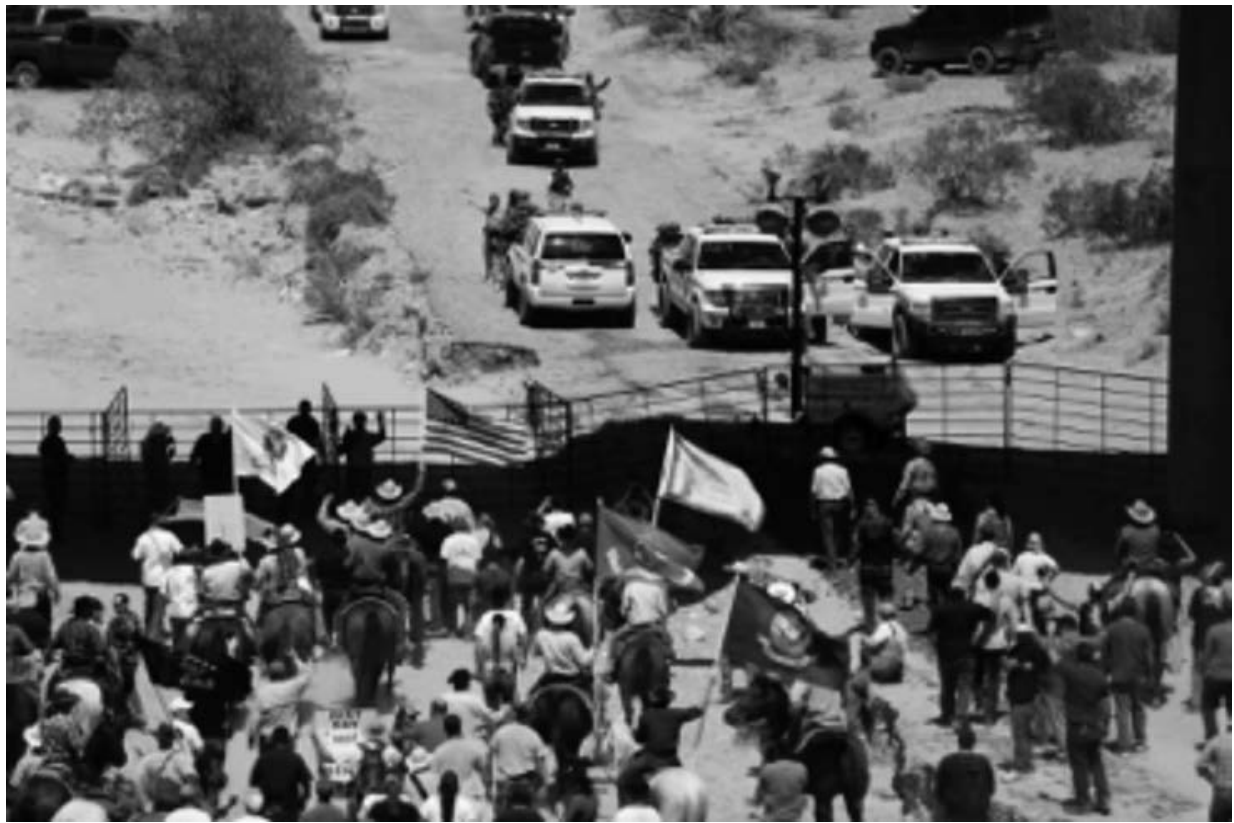

Fuente: Steve Marcus/Reuters/Corbis

Sus alianzas estratégicas más importantes en México son con el Frente Popular Francisco Villa Independiente, organización comunitaria con una base de 100000 miembros en la Ciudad de México, y con el Consejo Nacional Urbano y Campesino, organización comunitaria con base urbana y rural de 30000 miembros en Tlaxcala.

La MSN adopta prácticas transgresoras no solo por su alcance e intercambio transnacional, sino también por moverse más allá de "espacios convidados e inventados" del activismo. En años recientes, predominantemente grandes Corporaciones Inmobiliarias de Responsabilidad Limitada (Limited Liability Corporations
- LLCs) comenzaron a adquirir edificios de apartamentos de alquiler en Albany Park, expulsando a los inquilinos que estaba allí. Se hicieron algunas mejoras y se colocaron de nuevo las unidades en la cima del mercado inmobiliario, a precios inaccesibles para los antiguos habitantes - produciendo lo que se conoce como un típico proceso de gentrificación-.

Para combatir esos procesos de gentrificación y remoción el Centro Autónomo de Albany Park utiliza instrumentos legales, disponibles a través de los "espacios convidados", para extender los plazos de arrendamiento y proteger los derechos legales de los inquilinos. Sin embargo, no territarias 38

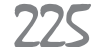


${ }^{6}$ Véase Ay \& Miraftab, 2016.

territarias 38 se limita a tales prácticas, también se moviliza a través de un abanico de "espacios inventados" de activismo. Lo que incluye acciones directas como protestas en frente de los bancos responsables por la gentrificación en sus vecindarios y por la crisis hipotecaria inmobiliaria nacional que dejó a muchas familias sin techo (figura 7).

El Centro Autónomo de Albany Park crea, también, mapas en tiempo real de la gentrificación, marcando los edificios que las LLCs adquieren, y organiza a los inquilinos de esos edificios en asociaciones específicas a cada una de estas edificaciones con el fin de sabotear las remociones $\mathrm{y} / \mathrm{o}$ las reformas de aquellas de donde fueron removidos. Sus prácticas transgresoras se asemejan al uso de la estrategia "espada y escudo". El escudo para extender la permanencia y proteger los residentes de bajos ingresos, la espada para generar acciones públicas contra los propietarios, en particular contra las LLCs que adquieren crecientes cantidades de unidades habitacionales en barrios en proceso de gentrificación como Albany Park.

Otro ejemplo puede ser las prácticas insurgentes de ciudadanos en Gezi Park, en Estambul, Turquía, durante el verano del 2013.

Recientemente, Denis Ay y yo publicamos un texto ${ }^{6}$ que documenta el éxito de espacios inventados de activismo usando actos performativos de insurgencia para

Figura 7. Protesta pacífica frente a los bancos para exponerlos por el hecho de provocar embargos y remociones 
detener la demolición del Parque Gezi y de la Plaza Taksim y su sustitución por un Centro Comercial.

El Parque Gezi y la adyacente Plaza Taksim, para aquellos que no están familiarizados con Estambul, conforman un espacio público clave para los residentes de Estambul. Es el eje comercial y de transporte público, y el mayor espacio público de la ciudad.

Los promotores multinacionales y el capital inmobiliario, entretanto, como parte de la agresiva neoliberalización del espacio urbano de Estambul, han puesto la mirada allí pensando en la apropiación de ese espacio para un uso de élite y sofisticado. Durante varias etapas de la planificación de este proyecto de renovación, los ciudadanos preocupados y las organizaciones civiles agotaron los canales liberales representativos de participación ciudadana (los llamados espacios convidados) para expresar su oposición. Pero, como se esperaba, esto no era más que una fachada de la agresiva agenda del capital para arrasar con todo, figurativa y literalmente, y así abrirse paso. Durante el día de la demolición, mientras tanto, los ciudadanos llegaron e inventaron nuevos medios para participar y ser escuchados; algunos espontáneos, otros organizados, enfrentaron una fuerte represión militar. Incluso así, ocuparon la plaza, instalaron su espacio comunal, imaginaron el espacio público como si fuera de ellos mismos y resistieron los avances del capitalismo.

Lo que es importante para mí, de ese ejemplo, son los aspectos performativos de la lucha y los espacios de activismo que ellos inventan - performatividad escenificada por aquellos que "no cuentan", para citar a Swyngeduow (2015)—. Una serie de tácticas basadas en el lugar, que simbólica y performativamente resiste al redesarrollo en la Plaza Taksim reinventó la plaza y le dio un nuevo significado a través del uso imaginativo de ese espacio público.

Por ejemplo, una forma no ortodoxa de protesta: permanecer de pie. Un hombre permaneció de pie por ocho horas consecutivas en la Plaza Taksim, frente al Centro Cultural Ataturk (AKM), donde hay una esfinge del tamaño de una pared de Ataturk, considerado el padre de la nación turca y de su moderno Estado y con las banderas nacionales del país a cada lado. El acto de permanecer de pie en cuanto miraba a la cara a esta figura disparó la memoria colectiva de los fundamentos de la Turquía moderna, que reverberaba entre muchas personas opositoras al Gobierno Nacional.

En cuanto el hombre de pie desorientó las fuerzas policiales, con respecto a la forma de manejar las supuestamente protestas pasivas de las masas "que estaban de pie", también creó una presencia corporal de las personas. Esa simple presencia de cuerpos en el dominio público, como Judith Butler y Athanasiou (2013) resaltan, genera una cierta fuerza performativa a través del "Nosotros estamos aquí", mensaje que también podría ser releído como "Nosotros aún estamos aquí", a despecho de los esfuerzos persistentes de desposesión y opresión. La protesta del Hombre de Pie territarias 38

227 


\section{territarias 38} 228 se volvió un acto innovador de la práctica ciudadana precisamente por causa del contexto histórico, espacial, político en el cual tuvo lugar y le dio significado.

La “Mesa en la Tierra” es otro ejemplo de espacios inventados de activismo. Un mes de lucha marcó el primer día del Ramadán y muchos pensaron que inevitablemente esto acabaría con las protestas llevadas a cabo en el Parque Gezi. Pero, por el contrario, las personas que estaban allí reinventaron el espacio de la calle más popular de Estambul (Istiklal), mezclando los ideales del movimiento del Parque Gezi con los rituales del Ramadán. Las personas ocuparon la línea del tranvía, que atraviesa la avenida Istiklal, y crearon la Mesa en la Tierra, como la llamaron, para quebrar su ayuno, recibiendo a cientos de personas que compartían su comida unos con otros. Este acto innovador de usar los rieles de la línea del tranvía, en medio del vecindario más vibrante de la ciudad y rodeados por restaurantes de alto lujo, fue clave para afirmar la presencia de ellos; el "nosotros aún estamos aquí" afectó, pero también evocó la imaginación de un espacio urbano más comunal y de un urbanismo humano.

Aunque esos movimientos no ofrezcan, de forma alguna, un plan urbanístico, sus prácticas son fundamentales para obstruir la bestia de la codicia urbana. Esas prácticas pueden, o no, permanecer válidas para otras luchas, otros tiempos y lugares, pero necesitamos inventar nuevas formas de acción, compartirlas, crear un repertorio, un idioma de planificación (para usar los términos de Ananya Roy) para empujar los límites de la imaginación y evocar un futuro alternativo que sea por la justicia espacial.

Figura 8. "Mesa en la tierra", Avenida Istiklal, julio del 2013

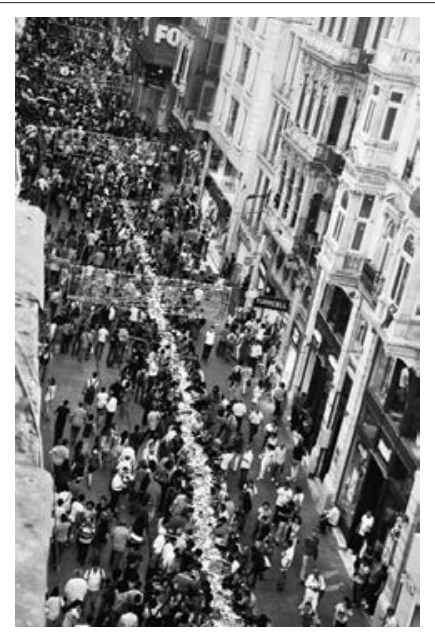

Fuente: Foto de Yagiz Karahan, 2013.

Las luchas por la imaginación y la decolonización del futuro, enfatizo, son el terreno político clave de la lucha. Ese es el acto III que abordo ahora, el cual tiene una implicación significativa para los educadores de la planificación.

\section{Acto III: Imaginación y urgencia en decolonizar el futuro}

Los escritos de intelectuales africanos nos enseñan que la liberación de las colonias sucede solo a través de lo que Fanon (1986; 1995 ) llama "decolonización de la mente" y "liberación de la imaginación”. La liberación necesita de una nueva consciencia, 
recuperada de la injuria moral colonial, de la profunda alienación que creía que el desarrollo de la colonia solamente podría suceder "bajo la condición de rechazarse a sí misma" y de que importara al por mayor escenarios y soluciones no africanas (Davidson, 1992).

Afirmo la necesidad de una nueva consciencia que libere las imaginaciones de la planificación. Eso requiere decolonizar la imaginación de la planificación cuestionando sus supuestos hegemónicos.

La lucha central con la que esta generación se enfrenta tiene lugar entre la expansión del dominio de la imaginación y su reducción. El futuro es inevitable. Es abierto y plural. Las personas necesitan de él como necesitan del aire, escribe Jan Pieterse (2000). Pero el futuro está también vacío; lo que significa que aquello que lo constituye depende de cómo es imaginado, susceptible de ser reinventado y "abierto por un horizonte de posibilidades". El futuro, a causa de su abertura y pluralidad, es un objeto de inmensa disputa, según Boaventura de Souza Santos (1995).

Pero la abertura sin fin, la pluralidad e imprevisibilidad del futuro también lo torna un territorio político, un sitio de fuerte contestación sobre el contenido que puede tener. Si no osamos imaginar lo inimaginable, entonces el futuro es menos abierto y más predeterminado como persistencia y perpetuación del presente.

La "colonización del futuro" es un concepto de importancia clave en esta discusión. Déjenme desarrollar esta idea: En las primeras colonias, la tierra, los recursos naturales y el trabajo esclavo eran objetos de creación de riqueza. En los años ochenta María Mies y sus colegas, Bennholdt-Thomsen y Von Werlhof (1988), provocadoramente escribieron Mujeres, la última colonia. Es decir, la colonización recayó sobre las mujeres para la obtención barata de su fuerza de trabajo y así crear más riqueza.

Hoy, sin embargo, argumento que el futuro es el que debe ser invocado como la última colonia; el futuro en cuanto territorio político, un "territorio" a ser " $\mathrm{OCu}^{-}$ pado" para protegerlo de imaginaciones totalitarias y de la eliminación de alternativas. El último sujeto de "ocupación colonial" o "acaparamiento" es entonces el futuro, y la lucha por su emancipación y decolonización es urgente.

Contrariamente a la idea de Francis Fukuyama (1992) sobre el fin de la historia, la cual cierra el futuro, existen las luchas de nuestros ciudadanos para superar tal encerramiento y abrir por el contrario el terreno para la imaginación y para concebir alternativas. El fin de la historia como lo conocemos, puede ser también el comienzo de la historia como la queremos. Para ello, algunas personas emplean acciones performativas que evocan la imaginación de un mundo diferente, así sea de forma momentánea o temporal. Otros, entre los nuevos movimientos sociales, se vuelven para la ficción científica, para los movimientos de justicia social.

En síntesis, si vamos a planificar un mundo más justo, y un urbanismo más humano, es clave la politización de la ima- territarias 38 229 
ginación y del futuro como un terreno de lucha por la justicia. El potencial de insurgencia para el urbanismo humano yace en la normalidad que él interrumpe y en el nuevo sentido común que ayuda a crear.

Y ahora, el acto final: cuáles son las implicaciones de esos debates para la enseñanza de la planificación.

Me enfoco en tres puntos principales que emergen de visiones específicas, que he compartido durante la última hora:

- Primero, en el núcleo de enseñanza de la planificación progresista debe existir un abordaje relacional que promueva un curriculum transgresor tanto en el contenido como en los modos de conocimiento.

- Segundo, una enseñanza de la planificación que mire el futuro necesita preparar los estudiantes con lenguajes que los conecten a diversos actores, que disputen la forma de modelar el hábitat humano.

- Tercero, como académicos de la planificación debemos usar cada oportunidad para estimular la imaginación y decolonizar el futuro.

\section{Déjenme explicar esto:}

Primero, necesitamos adoptar un abordaje relacional. Un abordaje relacional en la enseñanza de la planificación expone las injusticias y desigualdades por transgresión del tiempo, del lugar y de las formas de acción.
Para combatir una comprensión parroquial del desarrollo, un abordaje relacional promueve una comprensión transnacional e historicizada a través de todas las áreas del curriculum.

Este abordaje observa el lugar local como poroso, no como un territorio confinado o aparte. Va más allá del nacionalismo metodológico de los estudios urbanos y del pos-nacionalismo de los estudios globales para exponer el costo global del desarrollo local.

Un currículo relacional no enseñaría, por lo tanto, sobre revitalización sin gentrificación; no enseñaría sobre migración sin desplazamiento; no enseñaría sobre el presente sin un agudo sentido de la historia y no enseñaría sobre lo local sin revelar la jerarquía y su modo de conexión con el mundo. Una enseñanza relacional de la planificación politiza el curriculum, es politemporal y transnacional, proporciona a los estudiantes analogías y metáforas de la exclusión y del elitismo a través de la inclusión.

Segundo, necesitamos preparar a los estudiantes con varios lenguajes de la planificación que los conecten con actores diversos, los cuales disputan y modelan el futuro del hábitat humano.

Mi colega Carlos Vainer, de la Universidad Federal de Río de Janeiro, sugiere que la planificación podría ser entendida como un lenguaje, y lo que él llama de planificación conflictual ofrece un lenguaje técnico y discursivo de la planificación para los movimientos. Eso implica una enseñan-

\section{territarias 38}


za de la planificación que prepara a los estudiantes para involucrarse no solo con los espacios convidados, sino también con los espacios inventados de acción ciudadana.

La planificación, entendida como un campo de acción disputado por un conjunto de actores, reconoce los múltiples centros de poder, medios de acción y lenguajes. Los estudiantes que nosotros, como académicos, entrenamos pueden terminar en organizaciones sin ánimo de lucro de la sociedad civil, en autarquías municipales, en el mundo corporativo de las consultorías o del sector inmobiliario, o simplemente como ciudadanos preocupados, conduciendo sus propias luchas por una experiencia de vida humana y un medio de subsistencia dignos. Nuestros estudiantes requieren reconocer el significado de otros actores igualmente importantes en el proceso de construcción de ciudad. Ellos no pueden ser engañados por la criminalización de ciertas prácticas y espacios de acción.

Así pues, puede preguntarse: ¿qué deben hacer aquellos a quienes entrenamos para obtener un empleo como planificadores profesionales? La planificación insurgente no tiene proyectos urbanísticos; más allá de su estructura normativa no puede tener un proyecto urbanístico a la medida, ya que eso podría tirar por tierra la esencia de las prácticas imaginativas y relacionales que ella misma necesita. La planificación insurgente es específica del contexto y responde al conjunto de actores y relaciones que encuentra en un determinado contexto disputado. Como cada contexto posee su propia micropolítica e infrapolítica (para usar el término de Kelly Robin (1994), no existe una transmisión genérica de ciertas acciones a un planificador profesional.

Tercero, nuestro currículo necesita evocar la imaginación para avizorar un futuro alternativo, un futuro que incorpore un urbanismo humano.

Para una enseñanza transformadora de la planificación es útil contar con autores como Fanon porque muestra el papel que puede cumplir las subjetividades para reforzar o minar el discurso y la práctica de la cultura dominante. Fanon escribe sobre la colonización de la mente, de los valores y de las subjetividades a través de la falsa promesa de plena ciudadanía por hablar “el francés apropiado". En la enseñanza de la planificación las imaginaciones de los estudiantes son frecuentemente secuestradas por las experiencias de planificación euro-norteamericanas convencionales de la mainstream como la "planificación adecuada". El costo de no usar ideas e ideales convencionales y elitistas de la planificación es que no somos escuchados.

La eliminación de futuros alternativos no se hace siempre a través de la violencia directa, por ejemplo, por la criminalización de las alternativas. La remoción de prácticas alternativas de la planificación puede hacerse también a través de la violencia indirecta por medio del menosprecio de la alternativa - menospreciando las prácticas-. Por ejemplo, rotulando esas alternativas como "irreales y que, por lo tanto, no merecen un comprometimiento" o "sin vínculos con la realidad presente" territarias 38 231 
son argumentos que a menudo sirven como un medio efectivo para suprimirlas.

En esta era de "realismo", donde los ideales son menospreciados y soñar es estigmatizado, el ejercicio de la imaginación individual o colectiva de un mundo justo es de un valor pedagógico inestimable. Un ejemplo en ese sentido es mi grupo de estudiantes de primer semestre, a quienes solicité, en un sencillo pequeño ejercicio de grupo, que imaginaran cómo sería o se sentiría una ciudad justa: los estudiantes tuvieron dificultad para comprometerse con ese imaginario por cinco minutos. Para los docentes de la planificación la frontera de la lucha anticolonial y anti-hegemónica es en efecto la lucha por decolonizar las mentes y la imaginación de los estudiantes, para visualizar las posibilidades de un mundo diferente.

Para terminar me gustaría enfatizar que, por vivir en tiempos de crisis, tanto del capitalismo como de la planificación como profesión, estas nos compelen hacia nuevas oportunidades. La más importante oportunidad y desafío de la planificación progresista para tratar las injusticias espaciales consiste en osar imaginar un futuro radicalmente diferente que sea más justo y que corporice un urbanismo humano. Para eso necesitamos también de un repertorio de prácticas que puedan invocar tal imaginación y preparar los caminos para este tipo de urbanismo. El espacio de este congreso y su compartir transnacional de ideas e historias es una oportunidad única. Espero ansiosa por ello.

\section{Referencias}

Ay, D. \& Miraftab, F. (2016). Invented Spaces of Activism: Gezi Park and Performative Practices of Citizenship. En J. Grugel \& D. Hammett (Eds.), The Handbook of International Development (pp. 555-574). Londres: Palgrave MacMillan.

Bard, V. A. (2002). Covert Planning for Social Transformation in Indonesia. Journal of Planning Education and Research, 22(1), 15-25. doi: https://doi. org/10.1177/0739456x0202200102

Buchanan, I. (2000). Deleuzism: A metacommentary. Edinburgh: Edinburgh University Press.

Butler, J. \& Athanasiou, A. (2013). Dispossession: the performative in the political. Cambridge: Polity Press.

Davidson, B. (1992). The Black Man's Burden: Africa and the Curse of the NationState. New York: Times Books.

Fanon, F. (1986). Black Skin, White Mask. London: Pluto Press, 1986.

Fanon, F. (1995). The fact of Blackness. En B. Ashcroft, G. Griffiths \& H. Tiffin (Eds.), The Post-Colonial Studies Reader (pp. 291-294). New York: Routledge.

Friedmann, J. (2011). Insurgencies: essays in Planning Theory. New York: Routledge. Fukuyama, F. (1992). The End of History and the Last Man. New York: Free Press.

Mies, M., Bennholdt-Thomsen, V. \& Von Werlhof, C. (1988). Women: The Last Colony. London: Zed Books.

Miraftab, F. (2009). Insurgent Planning: Situating Radical Planning in 
the Global South. Planning Theory, 8(1), 32-50. doi: https://doi. org/10.1177/1473095208099297

Miraftab, F. \& Wills, S. (2005). Insurgency and Spaces of Active Citizenship: The Story of Western Cape Anti-Evictions Campaign in South Africa. Journal of Planning Education and Research, 25(2), 200-217. doi: https://doi. org/10.1177/0739456x05282182

Picture the homeless (200[¿]). Homeless people count vacant properties in Manbattan. New York: Picture the Homeless. Recuperado de http:/ / picturethehomeless. org/wp-content/uploads/2015/12/ Homeless_People_Count2.pdf

Pieterse, J. N. (2000). Global Futures: Shaping Globalization. London: Zed Books.

Rawls, J. (1971). A Theory of Justice. Cambridge, MA: Belknap, Harvard University Press.

Robin, K. (1994). Race Rebels: Culture, Politics, and the Black Working Class. New York: Free Press.
Sandercock, L. (1998). Framing Insurgent Historiographies for Planning. En L. Sandercock (Ed.), Making the Invisible Visible: A Multicultural Planning History (pp. 1-35). Berkeley: University of California Press.

Santos, B. S. (1995). Toward a New Common Sense: Law, Science and Politics in the Paradigmatic Transition. London: Routledg.

Svirsky, M. (2010). Introduction: Beyond the Royal Science of Politics. En M. Svirsky (Ed.), Deleuze Studies: Special Issue on Deeuze and Political Activism (pp. 1-6). Edinburgh: Edinburgh University Press.

Swyngedouw, E. (2015). Urban Insurgencies and the Re-Politicization of the Unequal City. En F. Miraftab, D. Wilson \& K. Salo (Eds.), Cities and inequalities in a Global and Neoliberal World (pp. 173-187). New York: Routledge.

Young, I. (1990). Justice and the Politics of Difference. Princeton: Princeton University Press. 
